\title{
Tracheal Bronchus with Persistent Pulmonary Hyper- tension of the Newborn: A Case Report
}

Se Hwan An, Min Ju Yi, Rita Yu, Ji-Hye Kim, Hey-Sung Baek, Ji-Eun Ban*, Kyoung Ja Lim, Seung Yang, Il-Tae Hwang, and Su Yeong Kim

Departments of Pediatrics and Radiology ${ }^{\dagger}$, Kangdong Sacred Heart Hospital, Seoul, Korea

Department of Pediatrics*, Ewha Womans University School of Medicine, Seoul, Korea

\section{ABSTRACT}

Tracheal bronchus is an uncommon anomaly in which an ectopic bronchus originates directly from the supracarinal trachea. It is usually an asymptomatic anatomical variant incidentally found on computed tomography or bronchoscopy. However, it can present with symptoms, such as chronic cough, wheezing, atelectasis, and recurrent pneumonia. We report a case of tracheal bronchus diagnosed in the neonatal period, in which the term baby presented with respiratory distress and persistent pulmonary hypertension of the newborn after birth, but no other congenital anomaly was found on further evaluation.

Key Words: Bronchi, Trachea, Infant, Newborn, Persistent fetal circulation syndrome

서론

기관기관지는 기관 분기부 상부의 기관에서 이소성 기관지가 분지되는 선천성 기도 기형으 로, 유병률은 $0.001 \%$ 에서 $2 \%$ 로 보고되며 대부분 기관 분기부의 상위 $2 \mathrm{~cm}$ 이내의 우측 기관 벽 에서 발생한다 ${ }^{1-3)}$. 기관기관지는 기관지경이나 전산화 단층 촬영(computed tomography, CT)에 의해 우연히 진단되는 경우가 많으며, 무증상인 경우 대부분 특별한 치료가 필요하지 않다. 증상 이 있는 소아 환자는 반복되는 폐렴이나 천명, 무기폐 등의 호흡기 증상을 보일 수 있으며, 감염 이 지속되고 약물 치료에 반응이 부적절할 경우 비정상적인 기관지와 폐엽의 수술적 절제가 권 장되기도 한다 ${ }^{2,4,5}$.

국내에서는 주로 증례로 문헌 보고되고 있으며 신생아 시기에 진단된 기관기관지는 대부분 선천성 기형이나 선천성 심질환을 동반한 환자에서 이를 평가하기 위해 시행한 검사에서 우연 히 발견된 경우였다 ${ }^{6,7)}$.

저자들은 다른 선천성 기형이 없이 태어난 신생아에서 출생 직후 발생한 호흡곤란 및 신생아 지속성 폐동맥 고혈압증으로 치료받던 중 동반된 기관기관지를 진단하였기에 보고하는 바이다.
Received: 1 September 2017

Revised: 18 October 2017

Accepted: 19 October 2017

Correspondence to: Su Yeong Kim Department of Pediatrics, Kangdong Sacred Heart Hospital, 150 Seonganro, Gangdong-gu, Seoul 05355, Korea Tel: +82-2-2224-2251

Fax: +82-2-482-8334

E-mail: kimsy@hallym.or.kr

Copyright(c)

By Korean Society of Neonatology.

All right reserved.

This is an Open-Access article distributed under the terms of the Creative Commons Attribution Non-Commercial License (http://creativecommons.org/licenses/ by-nc/4.0), which permits unrestricted non-commercial use, distribution, and reproduction in any medium, provided the original work is properly cited. 
증례

환자는 재태연령 38주 5일, 출생 체중 3,610 g (50-75 백분위)으 로 제왕절개를 통해 타병원에서 출생한 남아로, Apgar 점수는 1분 9 점, 5 분 10 점이었다. 출생 당시 자발호흡이 있었으나 빈호흡과 점차 심해지는 흥부함몰을 주소로 출생 4시간 째 본원으로 전원 된 후 신 생아중환자실로 입원하였다. 산모는 과거 임신력이 없는 34세 초산 부로 임신성 고협압 외에는 과거 병력 및 주산기 병력이 없었다. 임 신 중 철분제 외에 약물 복용력이 없었으며 가족력 상 특이 질환이 없었다. 환자는 입원 당시 혈압 $74 / 39 \mathrm{mmHg}$, 맥박수 148 회/분, 호 흡수 87 회/분, 체온 $36.5^{\circ} \mathrm{C}$ 이었으며, 비강 캐뉼라로 $3 \mathrm{~L} /$ 분의 산소를 공급하는 상태에서 산소포화도 $73 \%$ 였다. 진찰 소견 상 빈호흡과 흥 부 함몰 및 호기 시 신음(moaning sound)이 관찰되었다. 청진 시 호 흡음은 거칠었으며 심음은 규칙적이었고 심잡음은 들리지 않았다. 환자는 입원 당시 소량의 피가 섞인 구토 증상을 한 차례 보였다. 입 원 당시 시행한 일반혈액검사에서 백혈구 $27,200 / \mu \mathrm{L}$, 혈색소 $17.4 \mathrm{~g} /$ $\mathrm{dL}$, 헤마토크리트 $55.1 \%$, 혈소판 $323,000 / \mathrm{\mu L}$ 이었고, C-반응 단백 수 치 및 혈액응고검사는 정상이었다. 선천성 감염에 대한 혈청학적 검 사 결과 이상소견이 없었고 혈액 배양 검사에서 균이 동정되지 않았 다. 정맥 혈액 가스 분석 결과 $\mathrm{pH} 7.231, \mathrm{PCO}_{2} 44.7 \mathrm{mmHg}, \mathrm{PO}_{2} 50.5$ $\mathrm{mmHg}, \mathrm{HCO}_{3}{ }^{-} 18.9 \mathrm{mmol} / \mathrm{L}$ 이었으며 흥부 방사선 검사에서 전폐하 의 침윤 소견 및 공기 기관지 조영상을 보였다(Figure $1 \mathrm{~A}$ ). 전원 직 후 기관 삽관 및 인공호흡기를 적용하였으며, 기관지 내 튜브를 통 해 혈성 점액 분비물이 다량 흡인되었다. 필요한 흡입 산소 농도가 $50 \%$ 이상, Oxygen index 10.9로 신생아 호흡곤란 증후군 진단 후 폐 표면활성제를 투여하였다. 투약 직후에는 산소포화도가 개선 되고 Oxygen index 8.5, 필요한 흡입 산소 농도가 30\%까지 감소하며 호 전 반응을 보였으나(Figure 1B), 시간이 지나며 점차 필요한 산소 요 구량이 증가하며 Oxygen index 20.3으로 증가하고 흥부 방사선 촬 영에서 더딘 호전 소견으로 폐표면활성제를 재투여하였다. 출생 20 시간 째 빈번한 산소포화도 감소로 $80 \%$ 이상의 산소 공급이 필요하 였고, 동맥관 전후의 산소포화도 차이가 10-15\% 이상으로 지속되 었으며 울고 보채면 더욱 심해지는 양상을 보였다. 심초음파 검사에
서 약 $3.5 \mathrm{~mm}$ 의 동맥관을 통한 우좌 단락 및 D-shape의 좌심실 소 견이 관찰되고 삼첨판 역류 속도 $3.5 \mathrm{~m} / \mathrm{s}$ 로 보고되어 신생아 지속적 폐동맥 고혈압증(persistent pulmonary hypertension of newborn, $\mathrm{PPHN}$ )을 진단하였다. 산화질소(nitric oxide, NO) 가스 흡입 치료를 $20 \mathrm{ppm}$ 에서 시작하여 $60 \mathrm{ppm}$ 까지 증가시켰으며, 지속적 혈압상 승제와 진정제 및 예방적 항생제(ampicillin, gentamicin) 투여를 시 작하였다.

입원 3일째 sildenafil $\left(\right.$ Viagra $\left.^{\circledR}\right)$ 경구 투여를 시작하였다. 기관 흡 인 시 지속적으로 소량의 객혈이 관찰되었고 일반혈액검사 결과 백혈구 $6,860 / \mu \mathrm{L}$, 혈색소 $13.5 \mathrm{~g} / \mathrm{dL}$, 헤마토크리트 $39.4 \%$, 혈소판 $170,000 / \mu \mathrm{L}$ 이었다. 간헐적으로 혈병(blood clot)을 동반한 진하고 노란 가래가 증가하였으며, 잦은 기관 내 튜브 막힘으로 교체가 필 요하였다. 입원 5일 째 백혈구 $40,170 / \mu \mathrm{L}, \mathrm{C}$-반응 단백 $49 \mathrm{mg} / \mathrm{L}(0-$ $5.0 \mathrm{mg} / \mathrm{L}$ )로 증가하여 piperacillin+tazobactam과 amikacin으로 항 생제를 교체하였다. 혈액 배양 검사에서 균은 동정되지 않았으며, 기관 흡인을 통한 가래 배양에서 사용중인 항생제에 감수성이 있는 Pseudomonas aeruginosa가 보고되어 인공호흡기 관련 폐렴을 진 단하였다. 입원 7일째 시행한 심초음파 검사에서 여전히 큰 동맥관 이 관찰되었으나 동맥관 및 난원공의 단락 방향이 좌-우로 변화하였 고, 편평하던 심실사이중격의 모습이 약간 호전된 것으로 보고되었 으며, 환자 상태의 안정으로 혈압상승제 감량과 기계환기 압력 감량 을 시작하였다. 입원 10 일째 산소포화도의 빈번한 감소로 시행한 흥 부 방사선 검사에서 우측 폐의 기흥이 관찰되어 흥관을 삽입하였다. 입원 19일째 혈액검사에서 백혈구 및 C-반응 단백 수치가 정상화되 고 가래배양 검사도 음성으로 전환되어 항생제 치료를 중단하였고 흥관을 제거하였다. 기관 흡인 시 가래 양상은 호전되었으나 끈적 한 핏덩어리 양상의 분비물이 간헐적으로 관찰되었다. 입원 23 일째 모든 혈압상승제를 중단하였고, 입원 25일째 산화질소(NO) 치료를 중단하였다. 입원 27 일째 기관 발관 후 비강 지속적 양압환기기를 적용하였다(Figure 1C). 입원 30일째 심초음파에서 좌우단락의 작 은 난원공과 동맥관이 관찰되었고 좌심실 박출량 $50 \%$ 로 폐동맥고 혈압이 호전되었다. 고유량 비강 캐뉼라로 변경하여 $25 \%$ 의 산소를 공급하다가 입원 37일째 모든 호흡 보조를 중단하였다. 입원 33일
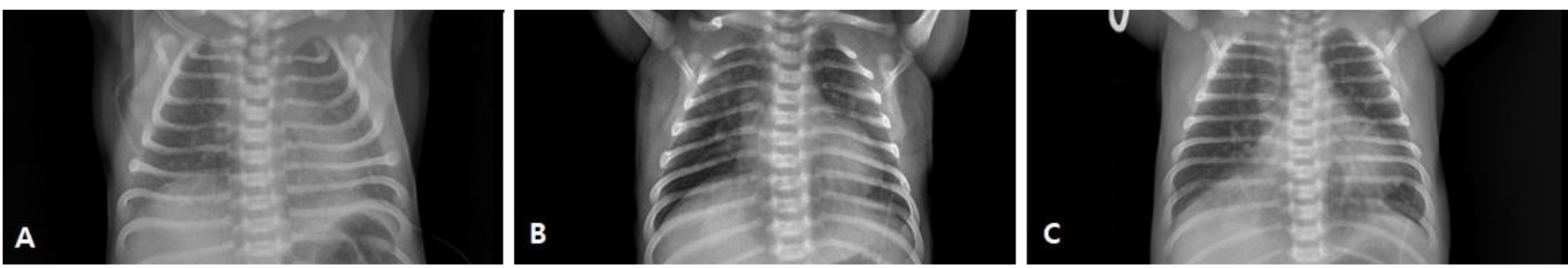

Figure 1. Chest X-ray. (A) On the $1^{\text {st }}$ day of life, the chest X-ray showed diffuse peribronchial increased opacities on both lungs. Surfactant deficiency disease was suspected. (B) On the $3^{\text {rd }}$ day of life, status post surfactant insertion, the chest X-ray showed decreased opacities on both lungs. (C) On the $27^{\text {th }}$ day of life, the chest X-ray showed infiltration is still remaining despite improved respiratory symptoms. 

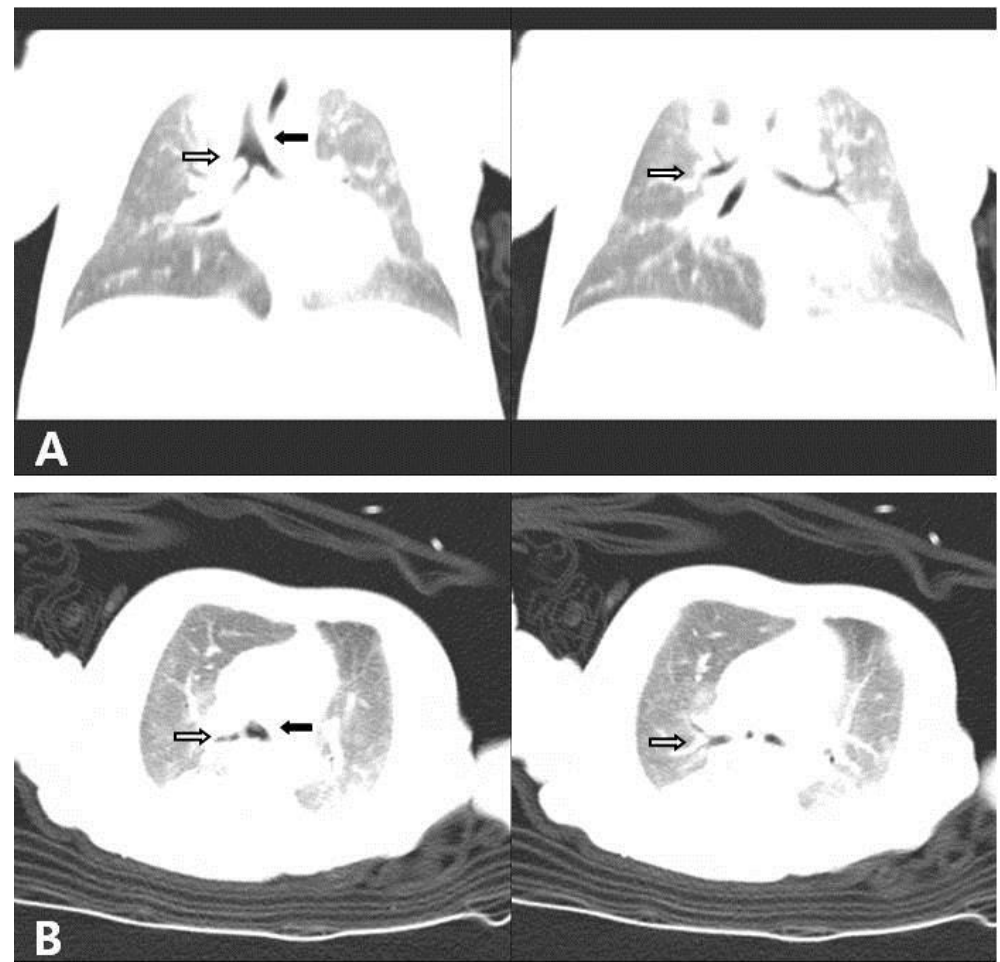

Figure 2. Chest CT scan. Serial images of lung window show abnormal upper right bronchus (white arrow) directly arising from the trachea (black arrow) in (A) coronal section and (B) sagittal section. Abbreviation: $\mathrm{CT}$, computed tomography.

째 반복적인 객혈과 객담 및 갑작스런 기흥을 평가하고자 시행한 폐 CT 결과 우측 상엽 기관지가 기관분기부 상부에서 기원하는 전위형 (displaced) 기관기관지가 보고되었다(Figure 2). 입원 35일째 시행 한 뇌 magnetic resonance imaging (MRI)에서 이상 소견이 없었으며 입원 41 일째 심초음파에서 동맥관이 닫힌 것을 확인하였고 환자는 sildenafil $\left(\right.$ Viagra $\left.^{\circledR}\right)$ 경구 투여를 지속하며 집으로 퇴원하였다.

생후 2개월에 외래에서 시행한 심초음파에서 작은 난원공 외에는 이상이 없는 것으로 보고되어 sildenafil (Viagra ${ }^{\circledR}$ ) 경구 투여를 중단 하였다. 환자는 현재 생후 7 개월로 외래에서 추적 관찰 중이며, 보호 자가 호소하는 호흡기 증상이 없으며 외래 검진 결과 정상적인 호흡 소견을 보였다. 몸무게 75 백분위, 신장 50 백분위였고, 정상 발달 소 견을 보이고 있다.

\section{고찰}

기관기관지는 기도 기형의 일종으로 1785 년 Sandifort가 처음으 로 기관에서 발생한 우상엽 기관지를 보고하였다 ${ }^{8)}$. 최근에는 기관 혹은 주기관지에서 분지하여 상엽의 환기를 담당하는 기관지의 기 형 전체를 일컬어 기관기관지라고 하고, 기관에서 분지하는 기관지
만을 참기관기관지(true tracheal bronchus)로 구분하여 말하기도 한 달. 돼지나 몇몇 반추동물에서 우상엽 기관기관지가 정상적인 구 조로 존재하기에 돼지 기관지(porcine bronchus 혹은 pig bronchus) 로 불리기도 한다. 기관기관지의 발생 빈도는 기관지영상검사, 기 관지내시경, 부검을 통한 연구에서 $0.001-2 \%$ 로 보고되고 있으며 ${ }^{1,2)}$, 윤상연골과 기관분기부 사이의 전 구간에서 발견될 수 있으나 대부분은 기관지 분기에서 $2 \mathrm{~cm}$ 이내의 기관벽에서 기원하며 우 측 기관기관지가 좌측에 비해 유병률이 높다 ${ }^{3,10}$. 기관기관지는 상 엽기관지가 기관에서 분지되는 경우를 전위형 기관지(displaced bronchus), 정상 기관지보다 이소성 기관지의 수가 많은 경우 과다 형(supernumerary bronchus)으로 분류하며, 전위형 기관지의 발생 빈도가 $75 \%$ 가량으로 더 높은 것으로 보고되고 있으나 두 형태의 임 상적 의의는 명확하지 않다 ${ }^{1)}$.

기관기관지를 가진 환자는 선천성 기형을 동반하는 경우가 많다 고 알려져 있는데, 선천성 심질환이 동반된 경우가 빈번하며 증후군 등의 유전적 질환 및 호흡기와 위장관계, 근골격계의 이상이나 무비 증, 기관식도루, 폐동맥 이상, Vertebral, anal, cardiac, tracheoesophageal, renal and limb (VACTERL) 연관 등을 동반한 증례들이 보 고되어 있다, ${ }^{5,610-13)}$.

국외의 한 연구에서 9,781 명이 시행한 다중검출기 전산화 단층촬 
영(Multi-detector computed tomography, MDCT) 검사를 분석한 결 과 30 명 $(0.31 \%)$ 의 기관기관지 발생 빈도를 보고하였으며, 환자의 연 령은 4-79세(평균 51세)로 다양하였다 ${ }^{14)}$. 기관지내시경을 시행한 16 세 이하의 소아 5,970 명을 분석한 국외 연구에서는 $0.95 \%$ 의 발생 빈 도를 보고하였는데, 대부분이 동반 증상이 없었으며 $61.5 \%$ 가 선천 기형을 가지고 있었다 ${ }^{13)}$. 다양한 이유로 MDCT 검사를 시행한 3,187 명의 7 세 미만의 소아를 대상으로 분석한 한 연구는 중 $1.51 \%$ 의 기 관기관지 유병률을 보고하였으며, 이 중 $87.5 \%$ 의 환자가 선천성 심 질환이 동반되어 있었다 ${ }^{12)}$. 국내에서는 주로 증례 보고로 문헌 보고 되고 있으며 대규모 연구는 부족한 실정으로, 성인을 대상으로 기관 기관지를 진단한 연구에서 각기 $0.1 \%{ }^{15)}, 0.58 \%{ }^{16)}$ 의 유병률을 보고 하였다. 소아를 대상으로 한 국내 연구 ${ }^{6}$ 에서 흥부 CT를 통해 기관기 관지로 진단 받은 19 례를 분석하였는데, 환자의 연령은 2 일에서 14 세(평균 51 개월)로 환자의 $89.5 \%$ 가 선천성 기형이 있었고 $84.2 \%$ 가 선천성 심혈관계 기형이 동반되어 있었다. 환자들 대부분 동반된 기 형의 평가를 위해 시행한 흥부 CT에서 우연히 기관기관지가 발견되 었으며, 객담, 천명, 반복적인 호흡기 감염 등의 증상이 있었던 경우 는 $31.6 \%$ 였다 ${ }^{6}$.

기관기관지 환자의 경우 대부분 특별한 증상을 보이지 않아 검사 를 통해 우연히 진단되는 경우가 많다. 과거에는 기관지내시경이나 기관지조영술에 의해 진단되었으나, 최근엔 MDCT가 이러한 침습 적 검사를 대신하고 있다 ${ }^{2,3,9,14)}$. 소아에서 기관기관지가 발견될 때 반복적인 감염, 천명과 만성 기침 같은 호흡기계 증상으로 진단되는 경우가 성인에 비해 많은 편이다 ${ }^{4)}$. 이외 동반되는 다른 증상으로 객 혈, 기관지 확장증, 폐기종, 낭종성 폐 형성증, 폐 방선균증이 보고된 바가 있다 ${ }^{1,17)}$. 기관기관지가 동반된 환자에서 반복적인 폐렴, 만성 기관지염, 기관지 확장증과 같은 염증상태가 호발하는 이유는 기형 으로 인해 관련 기관지에서 국소적 배출이 저하되기 때문으로 알려 져 있다 ${ }^{1)}$. 증상이 없이 지내던 기관기관지 환자의 경우 마취 및 기관 내 삽관 시 이소성 기관지의 폐쇄에 의해 폐허탈 혹은 우상엽의 과 팽창을 일으키는 것이 보고되어 있어 수술 등 기관 내 삽관이 필요한 경우 기관 내 튜브 위치에 대해 의료진의 주의를 요한다 ${ }^{2)}$.

본 증례에서 환자는 출생 당일 입원 당시 소량의 객혈이 관찰되었 으며 기관 내 삽관 후에도 지속적인 객혈과 객담이 관찰되었다. 소 아에서 객혈은 흔한 증상이 아니며, 최근 체계적 문헌 고찰에 의하면 감염, 심질환, 종양 등이 흔한 원인이며 특히 폐렴, 기관지염이 가장 흔한 원인으로 보고되었다 ${ }^{18)}$. 환자의 경우 선천성 폐렴의 증거가 없 는 상태에서 생후 5일 째 폐렴을 진단하였으며, 출생 24시간 이전에 발생한 신생아 지속성 폐동맥 고혈압은 통상적인 경과와 달리 치료 중 호전 및 악화를 반복하며 생후 3주 이후까지 지속되었다. 신생아 지속성 폐동맥 고혈압은 만삭아에서 일반적으로 산화질소(NO) 치 료를 포함한 혈 역학적 보존 치료를 시행하며 생후 1-2주 이내 호전 되는 것이 일반적인 경과이다 ${ }^{19)}$. 신생아 지속성 폐동맥 고혈압은 폐
혈관의 저항을 상승시키는 다양한 원인에 의하여 발생할 수 있으며, 폐혈관의 비정상적인 수축을 초래하는 감염, 태변흡인증후군, 신생 아 호흡곤란 증후군이나 선천성 횡격막탈출 등으로 인한 폐혈관 형 성부전 혹은 원인 미상의 폐형성 부전이 잘 알려진 원인이다 ${ }^{19,20)}$.

기관기관지를 가진 환자가 직접적으로 신생아 지속성 폐동맥 고 혈압을 일으킨 증례는 아직 보고된 바가 없으나, 감염의 경우 신생아 지속성 폐동맥 고혈압을 일으키는 흔한 원인이며, 호흡기계의 선천 성 기형을 가진 경우 신생아 지속성 폐동맥 고혈압의 중증도가 높아 져 사망률이 유의하게 증가하는 것으로 보고되고 있다 ${ }^{19,20)}$. 본 증례 의 환자는 출생 직후 발생한 신생아 호흡곤란 증후군으로 인해 신생 아 지속성 폐동맥 고혈압이 발생하였을 것으로 추정되며, 출생 시부 터 객혈, 객담의 호흡기계 증상을 보였던 기관기관지에 의해 관련 기 관지 및 폐상엽에서 배출이 저하되었을 뿐 아니라 감염 합병증에 의 해 신생아 지속성 폐동맥 고혈압이 더욱 악화되어 통상적인 경우보 다 위중하고 오래가는 경과를 보인 것으로 생각된다. 또한 경과 중 기계 환기 압력이 높지 않고 감량하던 중이었음에도 갑작스런 우폐 의 과팽창 및 기흥이 발생한 것 역시 기관 내 튜브에 의해 일시적인 이소성 기관지의 폐쇄가 원인이었을 것으로 생각된다.

본 증례의 환자는 항생제 치료를 포함한 보존적인 치료로 증상이 호전되어 기관기관지에 대한 추가적 치료를 시행하지 않았다. 대부 분의 기관기관지 환자는 보존적으로 치료가 가능하지만, 기관지 협 착증이 동반되었거나 기관지확장증이 있는 경우 반복적인 폐렴 또 는 객혈이 발생하였을 때 수술적 절제가 고려될 수 있다 ${ }^{2,5)}$.

저자들은 다른 기형이 없는 신생아에서 출생 직후 신생아 지속성 폐동맥 고혈압증과 호흡기계 합병증을 동반한 기관기관지를 진단한 사례를 경험하였기에 보고하는 바이다. 신생아 시기에 원인이 명확 하지 않은 지속되는 호흡기 증상과 합병증이 관찰될 경우 선천성 호 흡기계 기형에 대한 감별이 시행되어야 할 것이다.

\section{REFERENCES}

1) Ghaye B, Szapiro D, Fanchamps JM, Dondelinger RF. Congenital bronchial abnormalities revisited. Radiographics 2001; 21:105-19.

2) Doolittle AM, Mair EA. Tracheal bronchus: classification, endoscopic analysis, and airway management. Otolaryngol Head Neck Surg 2002;126:240-3.

3) Lee EY, Restrepo R, Dillman JR, Ridge CA, Hammer MR, Boiselle PM. Imaging evaluation of pediatric trachea and bronchi: systematic review and updates. Semin Roentgenol 2012; 47:182-96.

4) Schweigert M, Dubecz A, Ofner D, Stein HJ. Tracheal bronchus associated with recurrent pneumonia. Ulster Med J 2013;82:946. 
5) McLaughlin FJ, Strieder DJ, Harris GB, Vawter GP, Eraklis AJ. Tracheal bronchus: association with respiratory morbidity in childhood. J Pediatr 1985;106:751-5.

6) Kim YS, Um TM, Son SK, Kim HY, Kim YW, Park HJ. The clinical consideration of tracheal bronchus detected by computed tomography scan in children. Pediatr Allergy Respir Dis 2012;22: 411-6.

7) Jeong JH, Park MS, Kim HM, Park JT, Chung JH, Choi BW, et al. A case of tracheal bronchus associated with bilateral superior vena cava anomaly. Tuberc Respir Dis 2002;53:337-43.

8) Kubik S, Muntener M. Bronchus abnormalities: tracheal, eparterial, and pre-eparterial bronchi. Fortschr Geb Rontgenstr Nuklearmed 1971;114:145-63.

9) Kim H, Kim YT, Jou SS, Lee WH. True tracheal bronchus: classification and anatomical relationship on multi-detector computed tomography. J Korean Soc Radiol 2017;76:264-72.

10) Wooten C, Patel S, Cassidy L, Watanabe K, Matusz P, Tubbs RS, et al. Variations of the tracheobronchial tree: anatomical and clinical significance. Clin Anat 2014;27:1223-33.

11) Sanchez I, Navarro H, Mendez M, Holmgren N, Caussade S. Clinical characteristics of children with tracheobronchial ano malies. Pediatr Pulmonol 2003;35:288-91.

12) Ming Z, Lin Z. Evaluation of tracheal bronchus in Chinese children using multidetector CT. Pediatr Radiol 2007;37:1230-4.

13) Ruchonnet-Metrailler I, Abou Taam R, de Blic J. Presence of tracheal bronchus in children undergoing flexible broncho scopy. Respir Med 2015;109:846-50.

14) Suzuki M, Matsui O, Kawashima H, Takemura A, Matsubara K, Hayashi N, et al. Radioanatomical study of a true tracheal bronchus using multidetector computed tomography. Jpn J Radiol 2010;28:188-92.

15) Won JH, Park JY, Kang TK, Park KS, Kim YJ, Kim CH, et al. A clinical experience of tracheal bronchus. Tuberc Respir Dis 1998;45:583-6.

16) Kim JC, Kim YJ, Kang BJ, Youn YD, Lee SY, Kwon YL, et al. The clinical evaluation of anomalous bronchi arising from the trachea and main bronchi. Tuberc Respir Dis 2005;59:664-9.

17) Costiniuk CT, Voduc N, de Souza C. Pulmonary actinomycosis in a male patient with a tracheal bronchus. Can Respir J 2011; 18:84-6.

18) Simon DR, Aronoff SC, Del Vecchio MT. Etiologies of hemoptysis in children: a systematic review of 171 patients. Pediatr Pulmonol 2017;52:255-9.

19) Rocha G, Baptista MJ, Guimaraes H. Persistent pulmonary hypertension of non cardiac cause in a neonatal intensive care unit. Pulm Med 2012;2012:818971.

20) Steurer MA, Jelliffe-Pawlowski LL, Baer RJ, Partridge JC, Rogers EE, Keller RL. Persistent pulmonary hypertension of the newborn in late preterm and term infants in California. Pediatrics 2017;139. doi:10.1542/peds.2016-1165. 